\title{
Carotid artery stent infection with Streptococcus agalactiae
}

Figure Carotid artery stent infection with Streptococcus agalactiae

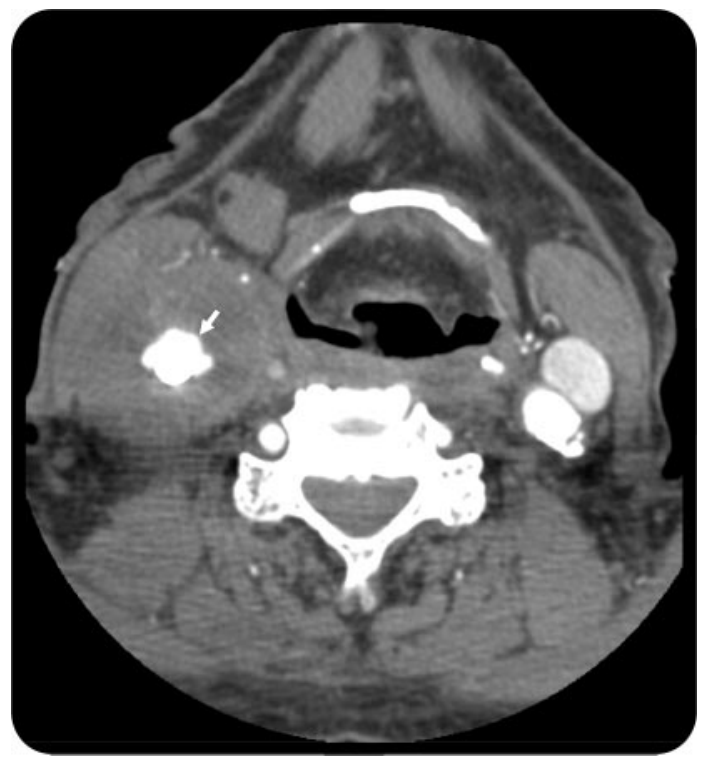

Right internal carotid artery stent infection. There is contrast extravasation (arrow) around the stent within a large neck mass; $S$ agalactiae was cultured from the infected carotid artery wall.

An afebrile 88-year-old man with a right internal carotid artery stent inserted 2 years previously in October 2006 presented acutely with right side visual loss and neck mass. CT angiogram showed contrast extravasation surrounding the stent (figure) and a large infected hematoma encapsulating the right common and internal carotid artery. Streptococcus agalactiae was cultured from the surgically excised carotid artery tissue and right eye vitreous fluid.

Carotid artery stent infection has been reported following neck irradiation. ${ }^{1}$ Carotid artery stent infection usually occurs after carotid artery wall injury; our case did not have an apparent injury, although we cannot rule this out.

Jamsheed A. Desai, MD, Saima F. Husain, MD, Omar Islam, MD, Albert Y. Jin, PhD, MD, Kingston, Canada

Disclosure: Dr. Desai, Dr. Hussain, and Dr. Islam report no disclosures. Dr. Jin received a Focus on Stroke CIHR/RxD Collaborative Research Program Fellowship.

Address correspondence and reprint requests to Dr. Albert Y. Jin, Department of Medicine (Neurology), Queen's University, clo Connell 7 , Division of Neurology, Kingston General Hospital, Kingston, Ontario, Canada K7L 2V7; ayj@queensu.ca

1. Kaviani A, Ouriel M, Kashyap VS. Infected carotid pseudoaneurysm and carotid-cutaneous fistula as a late complication of carotid artery stenting. J Vasc Surg 2006;43:379-382. 


\section{Neurology}

\section{Carotid artery stent infection with Streptococcus agalactiae}

Jamsheed A. Desai, Saima F. Husain, Omar Islam, et al. Neurology 2010;74;344

DOI 10.1212/WNL.0b013e3181cbcdaf

\section{This information is current as of January 25, 2010}

\section{Updated Information \&} Services

References

Subspecialty Collections

Permissions \& Licensing

Reprints including high resolution figures, can be found at: http://n.neurology.org/content/74/4/344.full

This article cites 1 articles, 0 of which you can access for free at: http://n.neurology.org/content/74/4/344.full\#ref-list-1

This article, along with others on similar topics, appears in the following collection(s):

\section{All Cerebrovascular disease/Stroke}

http://n.neurology.org/cgi/collection/all_cerebrovascular_disease_strok e

All Infections

http://n.neurology.org/cgi/collection/all_infections

Bacterial infections

http://n.neurology.org/cgi/collection/bacterial_infections CT

http://n.neurology.org/cgi/collection/ct

Information about reproducing this article in parts (figures,tables) or in its entirety can be found online at:

http://www.neurology.org/about/about_the_journal\#permissions

Information about ordering reprints can be found online:

http://n.neurology.org/subscribers/advertise

Neurology ${ }^{\circledR}$ is the official journal of the American Academy of Neurology. Published continuously since 1951, it is now a weekly with 48 issues per year. Copyright . All rights reserved. Print ISSN: 0028-3878. Online ISSN: 1526-632X.

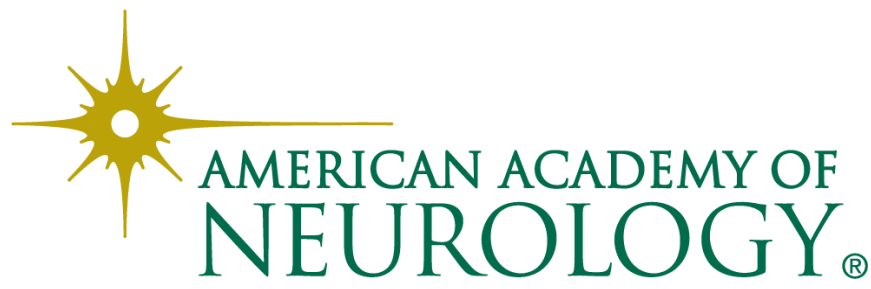

